\title{
Lung "holes" after cryobiopsy: a case report
}

\author{
Roberto Piro* ${ }^{*}$, Sofia Taddei, Matteo Fontana, Chiara Scelfo, Eleonora Casalini and Nicola Facciolongo
}

\begin{abstract}
Background: Transbronchial lung cryobiopsy is a safe technique increasingly used in the study of lung diseases. Until now, only a case of pneumatocele was described but this interesting condition is probably underestimated because $\mathrm{CT}$ scan is routinely not performed after transbronchial lung cryobiopsies.

Case presentation: We report a case of a woman presenting two pneumatoceles after lung cryobiopsies performed for the study of an interstitial lung disease. The finding was obtained with a CT scan performed because of the appearance of hemoptysis, four days after the biopsies.

Conclusions: Small cavitations could develop after cryobiopsies in the absence of an active infection. Studies that prospectively perform CT scan of the chest in patients who have undergone these samplings could be useful to know the incidence of iatrogenic lesions.
\end{abstract}

\section{Background}

In the last years, transbronchial lung cryobiopsies (TBLC) has emerged as a useful technique for the diagnosis of interstitial and other lung diseases [1]. Indeed, if properly performed, cryobiopsy is generally safer than surgical lung biopsy with lower contraindications, side effects, costs and hospitalization time [2, 3]. Recently, a case of a 69-year-old man subjected to TBLC that presented transient pulmonary cavitations with surrounding rims and fading ground glass infiltrates was reported [4]. CT scan was performed the day after the bronchoscopy because of chest pain. The histopathological exam of the biopsies showed nonspecific interstitial pneumonia (NSIP) with mixed dust nodules. This paper was the first reporting cavitated lesions after TBLC in non-transplanted patients. To date, the only similar cases concern lung abscesses [5] or large excavated lesions [6, 7]. Thus far, uniquely a lung transplanted population was studied in terms of incidence, evolution and characteristics of $\mathrm{CT}$ lesions following TBLC [8]. The general frequency of cavitated lesions after TBLC is unknown because CT scan is

*Correspondence: roberto.piro@ausl.re.it

Pulmonology Unit, Azienda Unità Sanitaria Locale - IRCCS di Reggio Emilia, Via Amendola 2, 42123 Reggio Emilia, Italy routinely not performed in the days after TBLC, so it is possible that changes occurring in the lung parenchyma after these biopsies may be unnoticed.

\section{Case presentation}

A 52-year-old female non-smoker patient was referred to our department because of cough and progressive dyspnea for over six months. She had a medical clinical history of psoriasis and primary biliary cholangitis. Physical examination revealed fine crackles bilaterally and was otherwise unremarkable. Lung function tests showed reduced diffusion capacity ( $52 \%$ of predicted value) while the other parameters resulted normal. Chest CT scan showed bilateral ground glass opacities in both lungs, especially in the lower lobes. On the recommendation of the multidisciplinary ILD board, the patient underwent TBLC, using a flexible bronchoscope inside a rigid tracheoscope. Fluoroscopy was used to guide the sampling: using a $1.9 \mathrm{~mm}$ cryobiopsy probe and freezing it for $5 \mathrm{~s}$, three biopsies were obtained in the lateral segment and one in the posterior segment of the right lower lobe. There was no immediate complication and, in particular, no bleeding occurred. The histological exam of the TBLC showed large fragments of lung parenchyma, diffusely involved by a mixed (fibrosing and cellular) NSIP 
pattern. Four days after the sampling, the patient presented with hemoptysis and she underwent the chest CT scan, revealing two cavitated lesions in the sampled sites (Fig. 1); they were absent in the previous scan. The lesions had a thin and regular wall, consisting with pneumatoceles [9]. The greater of them was $6 \times 4 \mathrm{~mm}$ and the smaller was $3 \times 4 \mathrm{~mm}$. These lesions were surrounded by ground glass areas, to a greater extent than was previously present; this was probably due to the addition of bleeding to the pre-existing manifestation of the underlying disease. The patient did not show signs of infection and she no longer presented hemoptysis so she was discharged without antibiotic therapy or prescription for further CT scan for this reason.

\section{Discussion and conclusions}

Generally, lung cavitation of acute/subacute onset are considered to be caused by infectious agents [10]. The unique published study evaluating the incidence, evolution and characteristics of CT lesions following TBLC was conducted in lung transplantated patients [8]. After obtaining 112 cryobiopsy samples, the authors observed 46 opacities greater than $10 \mathrm{~mm}$, including ground-glass, solid, cavitated or a combination of these lesions. Being a transplanted population, the findings of this study may not be traceable to other patients because of specific factors that could be involved, such as toxicity to immunosuppression or post-transplantation alteration of the lymphatic drainage. In the prospective follow up, most cavitated opacities resolved or evolved to solid residual opacities; only two cavitations remained unchanged after 3 and 6 months.

Our report reveals that little cavitations could develop after transbronchial lung cryobiopsy in the absence of an active infection, likely as a transient consequence of the trauma caused by the sampling, even if the pathogenic mechanism has not been investigated. The frequency of these conditions is probably underestimated. With the increasing use of this sampling technique, the reporting of findings like these becomes even more necessary. Even if in clinical practice CT scan after the biopsies should be performed only in case of new symptom onset, studies that prospectively perform CT scan of the chest in patients who have undergone cryobiopsies could be useful to understand their incidence.
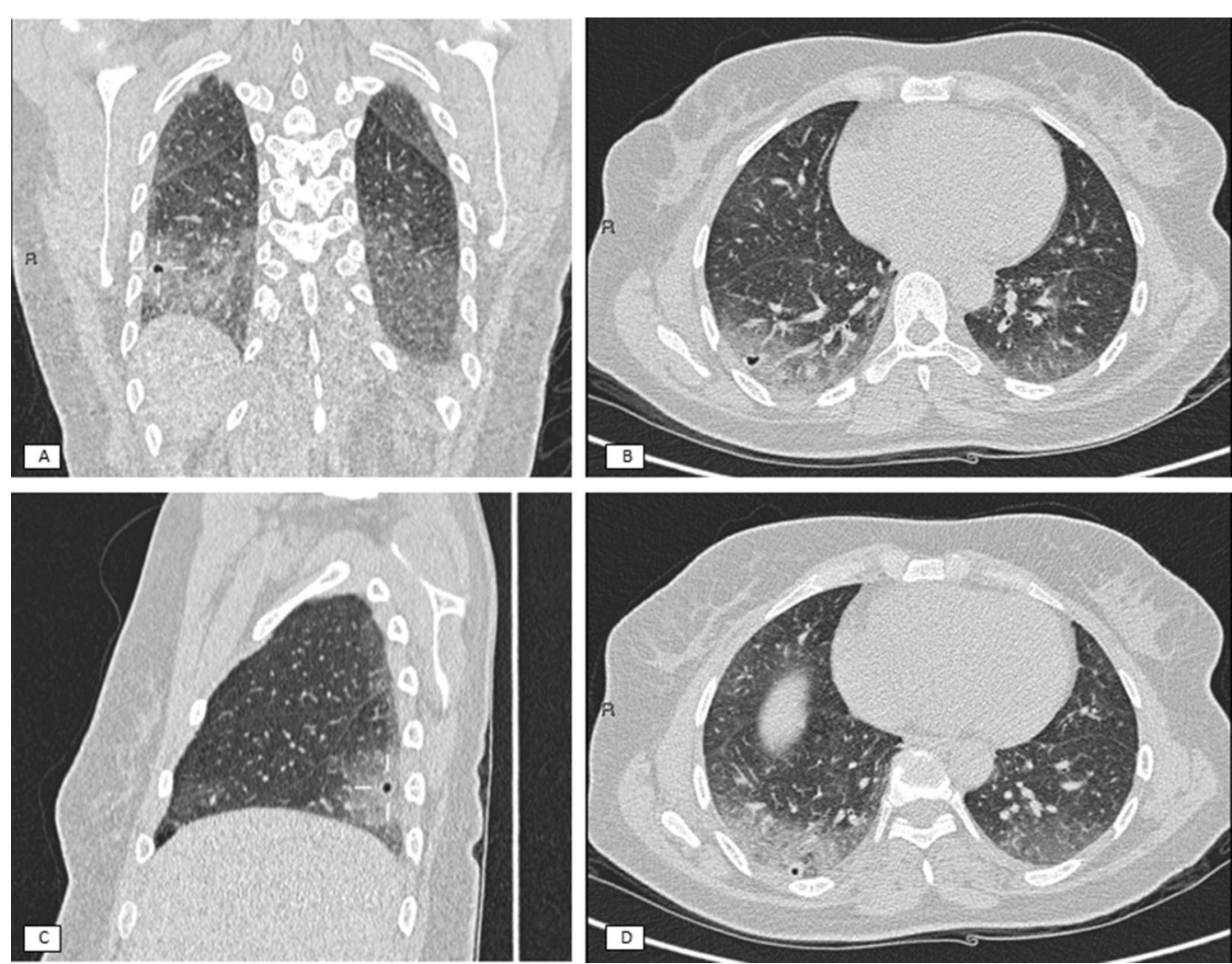

Fig. 1 CT scan five days after cryobiopsies. a Lateral pneumatocele (arrows) in coronal plane. b Lateral pneumatocele in sagittal plane. c Lateral pneumatocele (arrows) in axial plane. $\mathbf{d}$ Medial pneumatocele in axial plane 


\section{Abbreviations}

CT: Computed tomography; ILD: Interstitial lung disease; NSIP: Nonspecific interstitial pneumonia; TBLC:Transbronchial lung cryobiopsies.

\section{Acknowledgements}

The authors acknowledge Silvia Capobelli that contributed to the acquisition of the data.

\section{Authors' contributions}

RP conceived the work; RP and NF designed the work; RP, ST, MF, CS, EC and NF drafted the work and substantively revised it; ALL authors have agreed both to be personally accountable for the author's own contributions and to ensure that questions related to the accuracy or integrity of any part of the work, even ones in which the author was not personally involved, are appropriately investigated, resolved, and the resolution documented in the literature. All authors read and approved the final manuscript.

\section{Funding}

None.

\section{Availability of data and materials}

The datasets used and analyzed during the current study are available from the corresponding author on reasonable request.

\section{Declarations}

\section{Ethics approval and consent to participate}

Not applicable.

\section{Consent for publication}

The written consent for publication of clinical details and radiologic images was obtained from the patient.

\section{Competing interests}

The authors declare that they have no competing interests.

Received: 12 April 2021 Accepted: 16 August 2021

Published online: 23 August 2021

\section{References}

1. Babiak A, Hetzel J, Krishna G, Fritz P, Moeller P, Balli T, Hetzel M. Transbronchial cryobiopsy: a new tool for lung biopsies. Respiration. 2009;78(2):203-8. https://doi.org/10.1159/000203987.

2. Maldonado F, Danoff SK, Wells AU, Colby TV, Ryu JH, Liberman M, Wahidi MM, Frazer L, Hetzel J, Rickman OB, Herth FJF, Poletti V, Yarmus LB. Transbronchial cryobiopsy for the diagnosis of interstitial lung diseases: CHEST Guideline and Expert Panel Report. Chest. 2020;157(4):1030-42.

3. Avasarala SK, Wells AU, Colby TV, Maldonado F. Transbronchial cryobiopsy in interstitial lung diseases: state-of-the-art review for the interventional pulmonologist. J Bronchol Interv Pulmonol. 2021;28(1):81-92.

4. Jacobs B, Youness H, Kebbe J. Transbronchial cryobiopsy leading to transient pulmonary cavitations. J Bronchol Interv Pulmonol. 2019;26(3):219-21.

5. Skalski JH, Kern RM, Midthun DE, Edell ES, Maldonado F. Pulmonary abscess as a complication of transbronchial lung cryobiopsy. J Bronchol Interv Pulmonol. 2016;23:63-6.

6. Pathak V, Zhou C, George E. Cavitary lung disease following transbronchial biopsy using cryoadhesion in a patient with diffuse parenchymal lung disease. Lung India. 2019;36(1):60-2.

7. Castro HM, Wainstein EJ, Castro Azcurra R, Seehaus A. Pneumatocele following lung cryobiopsy. Arch Bronconeumol. 2021. https://doi.org/10. 1016/j.arbres.2021.01.010.

8. Loor K, Pallisa E, Culebras M, Deu M, Álvarez A, Sansano I, Berastegui C, Clofent D, Polverino E, de Gracia J. New opacities in lung allograft after transbronchial cryobiopsy. Respir Med. 2020;170:106043.

9. Hansell DM, Bankier AA, MacMahon H, McLoud TC, Müller NL, Remy J. Fleischner Society: glossary of terms for thoracic imaging. Radiology. 2008;246:697-722.

10. Gafoor K, Patel S, Girvin F, Gupta N, Naidich D, Machnicki S, Brown KK, Mehta A, Husta B, Ryu JH, Sarosi GA, Franquet T, Verschakelen J, Johkoh T, Travis W, Raoof S. Cavitary lung diseases: a clinical-radiologic algorithmic approach. Chest. 2018;153(6):1443-65.

\section{Publisher's Note}

Springer Nature remains neutral with regard to jurisdictional claims in published maps and institutional affiliations.

Ready to submit your research? Choose BMC and benefit from:

- fast, convenient online submission

- thorough peer review by experienced researchers in your field

- rapid publication on acceptance

- support for research data, including large and complex data types

- gold Open Access which fosters wider collaboration and increased citations

- maximum visibility for your research: over $100 \mathrm{M}$ website views per year

At BMC, research is always in progress.

Learn more biomedcentral.com/submissions 